\title{
VIGOR DE SEMENTES E ADUBAÇÃO NITROGENADA NA PRODUTIVIDADE E QUALIDADE FISIOLÓGICA DE SEMENTES DE TRIGO
}

\author{
José Henrique Bizzarri Bazzo ${ }^{1}$, Emanueli Bastos Garcia ${ }^{2 *}$, Jéssica de Lucena Marinho², Diogo \\ Gomes $^{3}$, Sérgio Ricardo Silva ${ }^{4}$, Claudemir Zucareli ${ }^{1}$

\footnotetext{
${ }^{1}$ Docente, Departamento de Agronomia, Universidade Estadual de Londrina, Londrina, Paraná, Brasil.

${ }^{2}$ Doutorando, Departamento de Agronomia, Universidade Estadual de Londrina, Londrina, Paraná, Brasil. *E-mail do autor correspondente: ebastosgarcia@gmail.com

${ }^{3}$ Mestrando, Departamento de Agronomia, Universidade Estadual de Londrina, Londrina, Paraná, Brasil.

${ }^{4}$ Pesquisador, Empresa Brasileira de Pesquisa Agropecuária, Centro Nacional de Pesquisa do Trigo, Londrina, Paraná, Brasil.
}

Recebido: 27/04/2020; Aceito: 02/04/2021

\begin{abstract}
RESUMO: A utilização de sementes de qualidade, associada à adubação nitrogenada aplicada em doses e momentos adequados, pode aumentar a produtividade e o potencial fisiológico das sementes produzidas. Neste sentido, objetivou-se avaliar o efeito do vigor de sementes utilizadas na semeadura associado a combinações de doses e épocas de aplicação de nitrogênio sobre a produtividade e a qualidade fisiológica de sementes de trigo. $\mathrm{O}$ experimento foi conduzido com a cultivar BRS Gralha-Azul, sob delineamento de blocos casualizados em esquema fatorial $2 \times 7$, com quatro repetições. Os tratamentos consistiram em dois níveis de vigor de sementes (alto e baixo) associados a sete combinações de doses e aplicação da adução nitrogenada (N1- sem N; N2- $40 \mathrm{~kg} \mathrm{ha}^{-1}$ de N no perfilhamento; N3- 80 $\mathrm{kg} \mathrm{ha}^{-1}$ de N no perfilhamento; N4- $40 \mathrm{~kg} \mathrm{ha}^{-1}$ de N na semeadura; N5- $80 \mathrm{~kg} \mathrm{ha}^{-1}$ de N na semeadura; N6- $40 \mathrm{~kg} \mathrm{ha}^{-1}$ de N na semeadura e $40 \mathrm{~kg} \mathrm{ha}^{-1}$ de N no perfilhamento; N7- $20 \mathrm{~kg}$ $\mathrm{ha}^{-1}$ de $\mathrm{N}$ na semeadura e $60 \mathrm{~kg} \mathrm{ha}^{-1}$ de $\mathrm{N}$ no perfilhamento). Foram avaliados: germinação, primeira contagem da germinação, comprimento e massa seca de plântulas, emergência de plântulas em areia, índice de velocidade e emergência, condutividade elétrica, massa de mil sementes e produtividade de sementes. A adubação com $20 \mathrm{~kg} \mathrm{ha}^{-1}$ de $\mathrm{N}$ na semeadura e 60 $\mathrm{kg} \mathrm{ha}^{-1}$ de $\mathrm{N}$ no início do perfilhamento foi o mais eficiente para a produção de sementes vigorosas da cultivar BRS Gralha-Azul. Sementes com alto vigor apresentam melhor potencial fisiológico. Os níveis de vigor de sementes e as combinações de épocas de aplicação e doses de nitrogênio não alteram a produtividade da cultura e a massa das sementes produzidas.
\end{abstract}

Palavras-chave: Triticum aestivum L.. Desempenho de plântulas. Doses de nitrogênio. Potencial fisiológico. Germinação.

\section{SEED VIGOR ASSOCIATED WITH NITROGEN FERTILIZATION ON YIELD AND PHYSIOLOGICAL QUALITY OF WHEAT SEEDS}

\begin{abstract}
The use of quality seeds, coupled with nitrogen fertilization applied at appropriate doses and times, can increase the productivity and the physiological potential of the seeds produced. In this sense, the objective of this study was to evaluate the effect of seed
\end{abstract}


vigor associated with combinations of doses and times of application nitrogen fertilizer on yield and physiological quality of wheat seeds. The experiment was conducted with the cultivar BRS Gralha-Azul, under a randomized complete block design in factorial $2 \times 7$, with four replications. The treatments consisted of two levels of seed vigor (high and low) doses associated to seven combinations (N1- without N; N2- $40 \mathrm{~kg} \mathrm{ha}^{-1} \mathrm{~N}$ tillering; $\mathrm{N} 3-80 \mathrm{~kg} \mathrm{ha}^{-1} \mathrm{~N}$ tillering; N4- $40 \mathrm{~kg} \mathrm{ha}^{-1}$ at sowing; N5- $80 \mathrm{~kg} \mathrm{ha}^{-1}$ at sowing; N6- $40 \mathrm{~kg} \mathrm{ha}^{-1}$ at sowing e $40 \mathrm{~kg}$ $\mathrm{ha}^{-1} \mathrm{~N}$ tillering; N7- $20 \mathrm{~kg} \mathrm{ha}^{-1}$ at sowing e $60 \mathrm{~kg} \mathrm{ha}^{-1} \mathrm{~N}$ tillering). Germination, first count, length of seedlings, dry mass of seedlings, seedling emergency in sand, emergency speed index, electrical conductivity, thousand sees mass and seed yield were determined. High vigor seeds have better physiological potential. Seed vigor levels and combinations of application times and nitrogen doses do not alter crop yield and seed mass.

Key words: Triticum aestivum L.. Seedling performance. Nitrogen doses. Physiological property. Germination.

\section{INTRODUÇÃO}

Sementes de qualidade são caracterizadas por apresentarem elevado potencial fisiológico, sanidade e altos percentuais de pureza física e genética. O potencial fisiológico das sementes está relacionado à capacidade destas em desempenhar suas funções vitais, reunindo informações sobre a germinação e o vigor (SCHUCH; KOLCHINSKI; CANTARELLI, 2008). O vigor refere-se ao conjunto de propriedades que atribuem às sementes o potencial para germinar, emergir e resultar em plântulas normais sob distintas condições ambientais (MARCOS FILHO, 2015).

A maior capacidade das sementes de alto vigor em resistir às condições adversas do ambiente resulta no rápido e uniforme crescimento de plântulas normais. Sementes com menor vigor apresentam maior porcentagem de plântulas anormais, o que compromete o estabelecimento do estande e o desempenho da cultura a campo (HENNING et al., 2010).

Segundo Santorum et al. (2013), sementes com capacidades de germinação análogas, podem apresentar comportamentos distintos na porcentagem de emergência de plântulas em condições de campo, devido aos diferentes níveis de vigor. A explicação para tal fato se deve às primeiras alterações nos processos bioquímicos, associados à deterioração das sementes, que normalmente ocorrem antes que se observe o declínio na capacidade germinativa (DELOUCHE; MATTHES; DOUGHERTY, 1973).

Para a obtenção de sementes com elevado desempenho fisiológico é indispensável o emprego de adequada adubação mineral, em especial a fertilização com nitrogênio (N) (BONO et al., 2008), a qual pode ter o seu efeito alterado pelas condições ambientais, pelo estádio de desenvolvimento da planta no momento da aplicação (CARVALHO; NAKAGAWA, 2012), dose e cultivar utilizada (TODESCHINI et al., 2016).

A disponibilidade de nutrientes para a planta pode interferir na qualidade das sementes, pois afeta diretamente a composição química, a formação do embrião e as estruturas de reserva que terão influência no desempenho fisiológico das sementes. Plantas bem nutridas 
possuem maior capacidade de produzir elevada quantidade de sementes e de melhor qualidade (SÁ, 1994).

O aumento da dose ou a antecipação da aplicação de nitrogênio na cultura do trigo, podem mitigar o efeito negativo do vigor das sementes, favorecendo a expressão da capacidade de compensação, sem alterar a produtividade e a qualidade das sementes. Neste sentido, objetivou-se avaliar o efeito do vigor de sementes utilizadas na semeadura associado a combinações de doses e épocas de aplicação do adubo nitrogenado sobre a produtividade e a qualidade fisiológica de sementes de trigo.

\section{MATERIAL E MÉTODOS}

O experimento foi conduzido em Londrina-PR, na fazenda experimental da Empresa Brasileira de Pesquisa Agropecuária - Embrapa Soja, em Latossolo Vermelho eutroférrico, localizado a $23^{\circ} 12^{\prime} 08^{\prime} \mathrm{S}, 51^{\circ} 10^{\prime} 36^{\prime \prime} \mathrm{O}$, com altitude de $564 \mathrm{~m}$. O clima, segundo a classificação de Köppen, é do tipo Cfa, subtropical úmido com verões quentes. Os dados de temperatura média diária e precipitação pluviométrica durante o período de cultivo são apresentados na Figura 1.

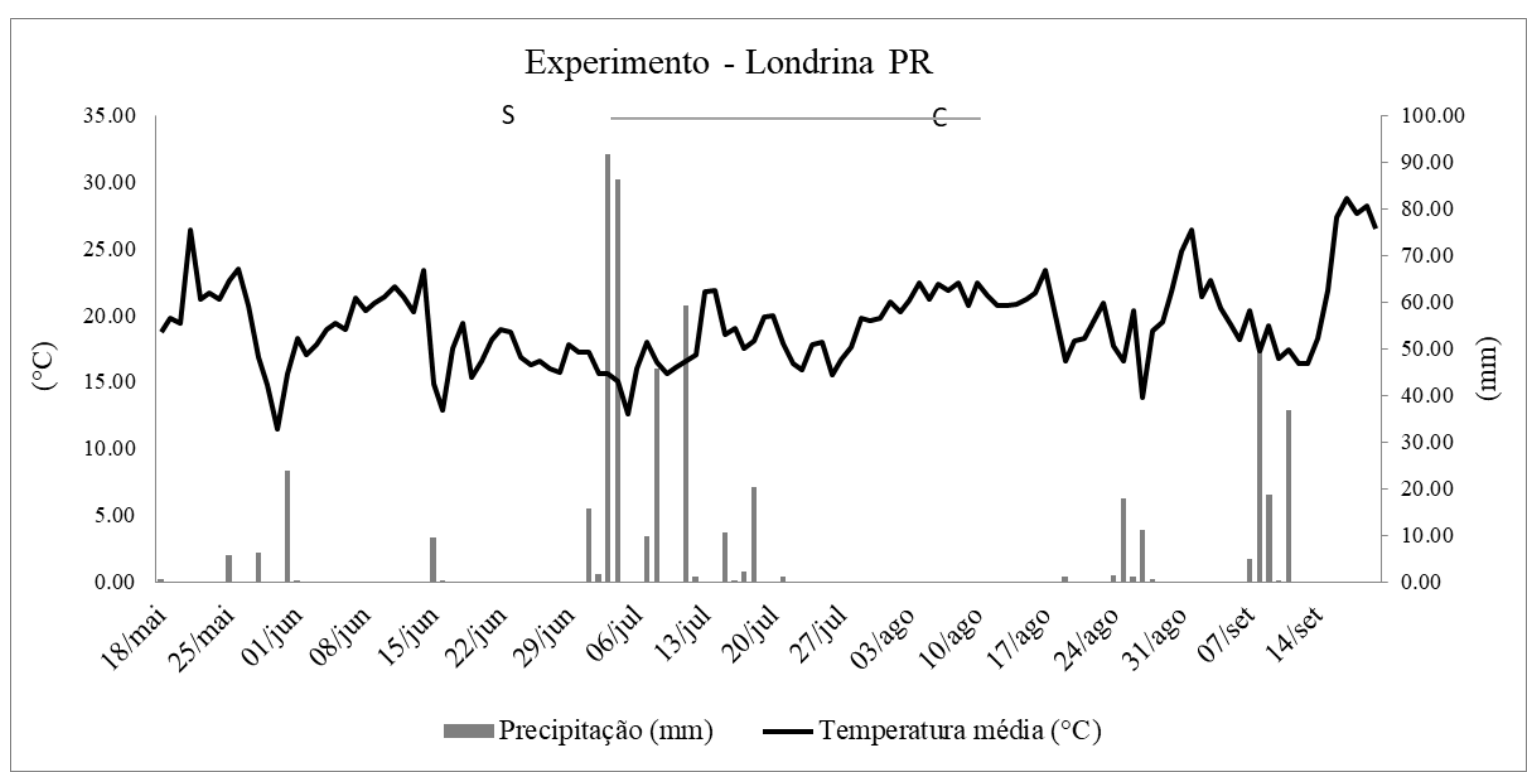

S: Semeadura; C: Colheita. S: sowing; C: harvest.

Figura 1. Temperatura média e precipitação pluviométrica diária para o período de condução do experimento em Londrina-PR. Average temperature and daily rainfall for the period of the experiment in Londrina-PR.

Fonte: Autoria própria. Own authorship.

Os resultados da análise química do solo na profundidade de $0-20 \mathrm{~cm}$, apresentaram as seguintes características: $\mathrm{pH}\left(\mathrm{H}_{2} \mathrm{O}\right): 5,3 ; \mathrm{P}\left(\mathrm{Mehlich}^{-1}\right): 31,7 \mathrm{mg} \cdot \mathrm{dm}^{-3} ; \mathrm{H}+\mathrm{Al}^{+3}: 3,46$ $\mathrm{cmol}_{\mathrm{c}} \cdot \mathrm{dm}^{-3} ; \mathrm{K}^{+}: 0,95 \mathrm{cmol}_{\mathrm{c}} \cdot \mathrm{dm}^{-3} ; \mathrm{Ca}^{+2}: 4,8 \mathrm{cmol}_{\mathrm{c}} \cdot \mathrm{dm}^{-3} ; \mathrm{Mg}^{+2}: 1,87 \mathrm{cmol}_{\mathrm{c}} \cdot \mathrm{dm}^{-3}$; CTC: 10,36 $\mathrm{cmol}_{\mathrm{c}} \cdot \mathrm{dm}^{-3}$; Saturação por bases (V): $66 \%$.

O delineamento experimental utilizado foi o de blocos casualizados em esquema fatorial $2 \times 7$, com quatro repetições. Os tratamentos consistiram em dois níveis de vigor de sementes (alto e baixo) associados a sete combinações de épocas e doses de adução nitrogenada (N1- 
sem N; N2- $40 \mathrm{~kg} \mathrm{ha}^{-1}$ de $\mathrm{N}$ no início do perfilhamento; $\mathrm{N} 3-80 \mathrm{~kg} \mathrm{ha}^{-1}$ de $\mathrm{N}$ no início do perfilhamento; N4- $40 \mathrm{~kg} \mathrm{ha}^{-1}$ de N na semeadura; N5- $80 \mathrm{~kg} \mathrm{ha}^{-1}$ de N na semeadura; N6- 40 $\mathrm{kg} \mathrm{ha}^{-1}$ de $\mathrm{N}$ na semeadura e $40 \mathrm{~kg} \mathrm{ha}^{-1}$ de $\mathrm{N}$ no início do perfilhamento; $\mathrm{N} 7-20 \mathrm{~kg} \mathrm{ha}^{-1}$ de N na semeadura e $60 \mathrm{~kg} \mathrm{ha}^{-1}$ de $\mathrm{N}$ no início do perfilhamento).

A cultivar de trigo utilizada foi a BRS Gralha-Azul, que se enquadra na classe comercial pão/melhorador. O genótipo possui ciclo de 124 dias, altura média de $83 \mathrm{~cm}$, bom potencial de perfilhamento, resistência à germinação em pré-colheita, resistência moderada a ferrugem da folha, ao oídio e ao vírus do mosaico (BASSOI et al., 2015).

As sementes consideradas de baixo vigor foram obtidas a partir de lotes de sementes com alto vigor, mediante envelhecimento acelerado. Para isso, as sementes foram colocadas em caixas plásticas, tipo gerbox, com suportes telados, contendo ao fundo $40 \mathrm{~mL}$ de água destilada. Após, foram incubadas em câmara para germinação de sementes tipo BOD (biochemical demand oxygen) sob temperatura de $42{ }^{\circ} \mathrm{C}$ por 48 horas.

As sementes não envelhecidas artificialmente (alto vigor) e as submetidas ao envelhecimento acelerado (baixo vigor) foram caracterizadas quanto à qualidade fisiológica inicial (Tabela 1), mediante os seguintes testes: germinação, primeira contagem da germinação, comprimento e massa seca de plântulas, condutividade elétrica, teste de frio, índice de velocidade de emergência e emergência de plântulas a campo.

Tabela 1. Atributos da qualidade fisiológica de sementes de trigo 'BRS Gralha-Azul' para caracterização dos lotes de sementes de alto vigor (AV) e de baixo vigor (BV). Physiological quality atributes of 'BRS Gralha-Azul' wheat seeds for characterization of high vigor (AV) and low vigor $(B V)$ seed lots.

\begin{tabular}{|c|c|c|c|c|c|c|c|c|c|}
\hline & G(\%) & \multicolumn{2}{|c|}{ PCG (\%) } & \multicolumn{2}{|c|}{ CTP (cm) } & \multicolumn{2}{|c|}{ CR (cm) } & \multicolumn{2}{|c|}{ CPA (cm) } \\
\hline Cultivar & AV & BV AV & $\mathrm{BV}$ & AV & $\mathrm{BV}$ & AV & BV & $\mathrm{AV}$ & $\mathrm{BV}$ \\
\hline \multirow[t]{3}{*}{ BRS Gralha-Azul } & 96,0 & $88,91,0$ & 74,0 & 25,4 & 16,6 & 14,8 & 8,1 & 10,6 & 8,5 \\
\hline & \multicolumn{2}{|c|}{ MSTP (mg) } & IVE & \multicolumn{2}{|c|}{$\mathrm{E}(\%)$} & \multicolumn{2}{|c|}{ TF (\%) } & \multicolumn{2}{|c|}{$\mathrm{CE}$} \\
\hline & $\mathrm{AV}$ & BV AV & BV & $\mathrm{AV}$ & $\mathrm{BV}$ & AV & BV & $\mathrm{AV}$ & $\mathrm{BV}$ \\
\hline BRS Gralha-Azul & 11,1 & $9,1 \quad 12,8$ & 11,6 & 86,0 & 78,0 & 89,0 & 85,0 & 22,0 & 26,0 \\
\hline
\end{tabular}

Nota: G: Germinação; PCG: Primeira contagem de germinação; CTP: Comprimento de plântula; CR: Comprimento de raiz; CPA: Comprimento de parte aérea; MSTP: Massa seca de plântulas; IVE: Índice de velocidade de emergência; E: Emergência; TF: Teste de frio e CE: Condutividade elétrica. PCG: first counting; G: Germination; CTP: Seedling length; CR: Root length; CPA: shoot length; MSTP: Dry seedling mass; IVE: Emergency speed index; E: Emergency; TF: Cold test and CE: Electrical conductivity.

Fonte: Autoria própria. Own authorship.

A semeadura foi realizada mecanicamente no dia 18/05, com densidade de 300 sementes viáveis $\mathrm{m}^{-2}$. As parcelas experimentais foram constituídas por dez linhas de seis metros de comprimento e espaçamento entre linha de $0,20 \mathrm{~m}$, com área útil de $12 \mathrm{~m}^{2}$. Para a colheita das sementes foram consideradas como área útil as seis linhas centrais, deixando-se como bordadura $0,5 \mathrm{~m}$ na extremidade final e inicial da parcela.

Para a adubação de semeadura foram utilizados $250 \mathrm{~kg} \mathrm{ha}^{-1}$ do fertilizante formulado 00-20-20 (N-P-K). A primeira parcela da adubação nitrogenada foi realizada no perfilhamento, manualmente no dia da semeadura e, a segunda parcela foi realizada da mesma 
forma no início da fase de perfilhamento, utilizando como fonte de nitrogênio o nitrato de amônio ( $32 \%$ de N), de acordo com as doses pré-estabelecidas para cada época de aplicação.

Os tratamentos fitossanitários para o controle de doenças e os demais tratos culturais foram realizados conforme a necessidade e recomendações para a cultura (SILVA; BASSOI; FOLONI, 2017). A colheita foi realizada no dia 18/09 após as sementes atingirem a maturidade de colheita, estádio caracterizado pelo endurecimento da cariopse, plantas com aspecto seco e sementes com umidade abaixo de $20 \%$.

A massa de mil sementes foi obtida mediante a contagem e pesagem de oito repetições de 100 sementes por parcela. A média desses valores foi multiplicada por 10 para obtenção do valor da massa de 1.000 sementes (BRASIL, 2009). A produtividade de sementes foi determinada com colheita das plantas contidas na área útil da parcela e após a trilha mecânica, as sementes foram pesadas e os dados transformados em $\mathrm{kg} \mathrm{ha}^{-1}$ a $13 \%$ de umidade. Para determinação da qualidade fisiológica das sementes foram realizadas as seguintes avaliações:

Germinação: realizada com oito repetições de 50 sementes, em papel germitest $^{\circledR}$, específico para germinação, umedecido com água destilada na proporção de 2,5 vezes a massa do papel seco. Os rolos de papel foram mantidos em germinador sob temperatura de $20{ }^{\circ} \mathrm{C}$. A avaliação constou de duas contagens, aos quatro dias (primeira contagem) e oito dias (contagem final) após a instalação do teste, computando-se a porcentagem de plântulas normais (BRASIL, 2009).

Comprimento de plântulas: foi realizado a partir da semeadura de quatro repetições de 20 sementes, no terço superior da folha de papel germitest ${ }^{\circledR}$, umedecido com água destilada, na proporção de 2,5 vezes a massa do papel seco. Os rolos de papel contendo as sementes permaneceram por cinco dias em germinador, à temperatura de $20^{\circ} \mathrm{C}$, quando foi avaliado o comprimento das plântulas normais, com auxílio de uma régua. Os resultados foram expressos em centímetros por plântula (NAKAGAWA, 1999).

Massa seca de plântulas: foi conduzido juntamente com o teste de comprimento de plântulas. As plântulas normais foram separadas do tecido de reserva, colocadas em embalagens de papel e levadas à estufa com circulação de ar forçada, regulada à temperatura de $80{ }^{\circ} \mathrm{C}$, durante 24 horas. Transcorrido o tempo, a massa seca foi mensurada em balança com precisão de 0,0001 g determinando-se assim a massa das plântulas normais. Os resultados foram expressos em mg por plântula (NAKAGAWA, 1999).

Emergência de plântulas em areia: o teste foi realizado com quatro repetições de 50 sementes por tratamento. A areia foi previamente lavada e, em seguida, disposta em bandejas plásticas. A semeadura foi realizada a $3,0 \mathrm{~cm}$ de profundidade. $\mathrm{O}$ teste foi conduzido em casa de vegetação do tipo Van der Hoeven, com temperatura média de $22^{\circ} \mathrm{C}$, e a umidade mantida com irrigações de acordo com a necessidade da cultura. A avaliação do número de plântulas normais emergidas foi realizada no décimo quinto dia, e os resultados expressos em porcentagem.

Índice de velocidade de emergência de plântulas: foi realizado juntamente com o teste de emergência de plântulas em areia por meio de contagens diárias do número de plântulas 
normais emergidas até a estabilização da emergência, segundo a fórmula proposta por Maguire (1962).

Condutividade elétrica: foi conduzido por meio do sistema de massa, com quatro repetições de 50 sementes. Foi determinada a massa das sementes e, estas colocadas em copos plásticos com $75 \mathrm{ml}$ de água deionizada e mantidas em BOD a $25^{\circ} \mathrm{C}$. Após 24 horas de embebição foi determinada a condutividade elétrica da solução com resultados expressos em $\mu \mathrm{S} \mathrm{cm}^{-1} \mathrm{~g}^{-1}$ (VIEIRA; KRZYZANOWSKI, 1999).

Os dados foram submetidos às análises de normalidade e homocedasticidade e, posteriormente, a análise de variância. As médias do vigor de sementes foram comparadas pelo teste $\mathrm{F}$, e das combinações de doses e épocas de adubação nitrogenada pelo teste de Tukey, a 5\% de probabilidade.

\section{RESULTADOS E DISCUSSÃO}

Houve efeito significativo da interação entre o vigor de sementes e a adubação nitrogenada para as características germinação, comprimento e massa seca de plântulas (Tabela 2). Para a primeira contagem da germinação verificou-se efeito isolado de ambos os fatores. As demais variáveis não apresentaram efeitos significativos para os fatores avaliados.

Tabela 2. Análise de variância para as variáveis de qualidade fisiológica das sementes de trigo da cultivar BRS Gralha-Azul, em função dos níveis de vigor de sementes e da adubação nitrogenada. Analysis of variance for the physiological quality variables of wheat seeds of the cultivar BRS Gralha-Azul, as a function of seed vigor levels and nitrogen fertilization.

\begin{tabular}{|c|c|c|c|c|c|c|c|c|c|}
\hline \multirow[b]{2}{*}{ Fonte de variação } & \multicolumn{9}{|c|}{ Características } \\
\hline & $\begin{array}{l}\mathrm{G} \\
(\%)\end{array}$ & $\begin{array}{l}\mathrm{PC} \\
(\%)\end{array}$ & $\begin{array}{c}\mathrm{CP} \\
(\mathrm{cm})\end{array}$ & $\begin{array}{l}\text { MSP } \\
(\mathrm{mg})\end{array}$ & $\begin{array}{l}\mathrm{EP} \\
(\%)\end{array}$ & $\begin{array}{l}\text { IVE } \\
(\%)\end{array}$ & $\begin{array}{c}\mathrm{CE} \\
\left.\mathrm{uS} . \mathrm{cm}^{-1} \cdot \mathrm{g}^{-1}\right)\end{array}$ & $\begin{array}{c}\text { MMS } \\
(\mathrm{g})\end{array}$ & $\begin{array}{l}\text { PROD } \\
\left(\mathrm{kg} \mathrm{ha}^{-1}\right)\end{array}$ \\
\hline Bloco & 26,30 & 22,57 & 0,58 & 0,13 & 28,07 & 0,84 & 40,21 & 4,71 & $684663,02 *$ \\
\hline Vigor (V) & $123,02^{*}$ & $164,57^{*}$ & $14,70 *$ & $1,46^{*}$ & 0,64 & 0,14 & 9,44 & 2,30 & 263526,90 \\
\hline Nitrogênio (N) & $28,72 *$ & $75,39 *$ & $11,64 *$ & $4,23^{*}$ & 16,57 & 0,32 & 38,70 & 3,28 & 99514,43 \\
\hline $\mathrm{V} * \mathrm{~N}$ & $27,22 *$ & 15,82 & $25,59 *$ & $1,60^{*}$ & 53,14 & 1,37 & 31,40 & 2,77 & 56175,59 \\
\hline $\mathrm{CV}(\%)$ & 3,44 & 4,18 & 6,19 & 8,86 & 5,88 & 9,91 & 18,70 & 5,58 & 8,62 \\
\hline
\end{tabular}

Nota: *significativo a 5\% de probabilidade pelo teste $\mathrm{F}$ para vigor e Tukey para nitrogênio. G: germinação; PC: primeira contagem da germinação; CP: comprimento de plântulas; MSP: massa seca de plântulas; EP: emergência de plântulas em areia; IVE: índice de velocidade de emergência; CE: condutividade elétrica; MMS: massa de mil sementes e PROD: produtividade de sementes. *significant at $5 \%$ probability by the $F$ test for vigor and Tukey for nitrogen. G: Germination; PC: first counting; CP: Seedling length; MSP: Dry seedling mass; EP: Emergency; IVE: Emergency speed index; CE: Electrical conductivity; MMS: mass of a thousand seeds and PROD: seed productivity.

Fonte: Autoria própria. Own authorship.

Para a germinação (Tabela 3), verificou-se que entre os níveis de vigor houve diferença significativa apenas em N2 e N4, com os maiores valores desta variável para sementes provenientes de plantas obtidas de sementes de alto vigor. Quanto aos resultados dentro do nível de alto vigor, verifica-se que não houve diferença entre as combinações de época e 
doses de aplicação de N. Já em sementes de baixo vigor, observa-se que o maior e o menor valor para a característica foram encontrados em N5 e N2, respectivamente.

Resultados estes se assemelham aos observados por Schuch et al. (1999) em estudos com adubação nitrogenada e níveis de vigor de sementes na qualidade fisiológica de sementes de aveia preta, em que ocorreu redução significativa nos valores de primeira contagem e germinação das sementes quando aplicados $40 \mathrm{~kg} \mathrm{ha}^{-1}$ de $\mathrm{N}$ no perfilhamento, o que foi justificado pelo aumento no acamamento das plantas.

Os resultados revelam que a adubação nitrogenada não apresentou efeito sobre a germinação de sementes oriundas de plantas originadas de sementes de alto vigor, entretanto favoreceu a germinação de sementes oriundas de plantas originadas de sementes de baixo vigor produzidas sem parcelamento da adubação e na maior dose de $\mathrm{N}$ na semeadura (80 kg $\left.\mathrm{ha}^{-1}\right)$, não apresentando diferença significativa na ausência da fertilização nitrogenada.

A ausência de resposta no teste de germinação às épocas e doses de aplicação de $\mathrm{N}$ das sementes de alto vigor em comparação às de baixo vigor, revela que, provavelmente, as plantas provenientes de sementes de alto vigor foram mais eficientes quanto à produção e translocação de fotoassimilados para suas respectivas progênies suprindo, dessa forma, a demanda de $\mathrm{N}$ no período inicial de desenvolvimento.

Uma melhor condição de nutrição da planta possibilita formação de uma semente mais resistente e redução do processo de deterioração, o que pode ser observado através do teste de germinação (NAKAO et al., 2018). A adubação nitrogenada tem ação eficiente e pronunciada sobre sementes de trigo, quando realizada antes da fecundação as respostas são mais intensas sobre a assimilação de reservas e aumento do teor de proteínas das sementes (MARCOS FILHO, 2015).

Quanto aos tratamentos N2 e N4, utilizando sementes de baixo vigor, verifica-se que a aplicação de $40 \mathrm{~kg} \mathrm{ha}^{-1}$ de $\mathrm{N}$ na ocasião da semeadura ou perfilhamento não foi suficiente para mitigar os prejuízos provocados pelo possível menor estande estabelecido e baixo vigor inicial de plântulas. Isto pode ser explicado pela alta exigência dessa cultivar em relação à adubação nitrogenada, como mencionado por Todeschini et al. (2016), que observaram que a cultivar BRS Gralha-Azul apresentou alta capacidade de absorção e remobilização de N comparada a outras cultivares modernas de trigo, apresentando ponto crítico mínimo de absorção de $170 \mathrm{~kg}$ de $\mathrm{N} \mathrm{ha}^{-1}$ e máximo próximo a $216 \mathrm{~kg}$ de $\mathrm{N} \mathrm{ha}^{-1}$.

Os maiores valores de comprimento de plântulas (Tabela 3), para os tratamentos com alto vigor de sementes, foram observados em N2 e N5 Para baixo vigor de sementes, o maior comprimento de plântulas foi verificado em N7. Estes resultados contrapõem aqueles obtidos por Prando et al. (2012), que não observaram diferenças entre doses de 0 , 40 e $80 \mathrm{~kg} \mathrm{ha}^{-1}$ aplicado no perfilhamento sobre a qualidade fisiológica de sementes de trigo. Constata-se que as sementes produzidas por plantas originadas de sementes de baixo vigor foram beneficiadas com o parcelamento da adubação com 20 e $60 \mathrm{~kg} \mathrm{ha}^{-1}$ aplicadas na semeadura e perfilhamento, respectivamente, para o comprimento de plântulas. 
Tabela 3. Germinação (G), comprimento de plântulas (CP) e massa seca de plântulas (MSP) de trigo da cultivar BRS Gralha-Azul em função do vigor de sementes e da adubação nitrogenada. Germination $(G)$, Seedling length $(C P)$ and dry seedling mass (MSP) of wheat from cultivar BRS Gralha-Azul depending on seed vigor and nitrogen fertilization.

\begin{tabular}{|c|c|c|c|c|c|c|}
\hline \multirow{3}{*}{ Nitrogênio } & \multicolumn{6}{|c|}{ Vigor de sementes } \\
\hline & \multicolumn{2}{|c|}{$\mathrm{G}(\%)$} & \multicolumn{2}{|c|}{$\mathrm{CP}(\mathrm{cm})$} & \multicolumn{2}{|c|}{ MSP (mg) } \\
\hline & $\mathrm{AV}$ & $\mathrm{BV}$ & $\mathrm{AV}$ & $\mathrm{BV}$ & $\mathrm{AV}$ & BV \\
\hline N1 & $89 \mathrm{aA}$ & $91 \mathrm{abA}$ & $10,13 \mathrm{~dB}$ & $12,52 \mathrm{bA}$ & $4,89 \mathrm{cA}$ & $5,31 \mathrm{bcA}$ \\
\hline $\mathrm{N} 2$ & $92 \mathrm{aA}$ & $85 \mathrm{bB}$ & $15,22 \mathrm{aA}$ & $11,19 \mathrm{bB}$ & $7,03 \mathrm{aA}$ & $4,93 \mathrm{cB}$ \\
\hline N3 & $94 \mathrm{aA}$ & $91 \mathrm{abA}$ & $11,63 \mathrm{cdA}$ & $11,59 \mathrm{bA}$ & $4,94 \mathrm{cA}$ & $5,40 \mathrm{bcA}$ \\
\hline N4 & $95 \mathrm{aA}$ & $87 \mathrm{abB}$ & $13,10 \mathrm{bcA}$ & $12,44 \mathrm{bA}$ & $6,69 \mathrm{abA}$ & $6,22 \mathrm{abA}$ \\
\hline N5 & $94 \mathrm{aA}$ & $94 \mathrm{aA}$ & $15,12 \mathrm{aA}$ & $7,51 \mathrm{cB}$ & $6,22 \mathrm{abA}$ & $5,54 \mathrm{bcA}$ \\
\hline N6 & $91 \mathrm{aA}$ & $88 \mathrm{abA}$ & $10,47 \mathrm{dA}$ & $11,92 \mathrm{bA}$ & $5,62 \mathrm{bcA}$ & $5,63 \mathrm{bcA}$ \\
\hline N7 & $91 \mathrm{aA}$ & $91 \mathrm{abA}$ & $13,67 \mathrm{abB}$ & $14,97 \mathrm{aA}$ & $7,12 \mathrm{aA}$ & $7,23 \mathrm{aA}$ \\
\hline $\mathrm{CV}(\%)$ & \multicolumn{2}{|c|}{3,44} & \multicolumn{2}{|c|}{6,19} & \multicolumn{2}{|c|}{8,86} \\
\hline
\end{tabular}

Nota: Médias seguidas de mesma letra minúscula na coluna e maiúscula na linha não diferem entre si pelo teste de Tukey e pelo teste $\mathrm{F}(\mathrm{P}<0,05)$, respectivamente. AV: alto vigor; $\mathrm{BV}$ : baixo vigor; $\mathrm{N} 1$ : sem $\mathrm{N}$; $\mathrm{N} 2$ : $40 \mathrm{~kg} \mathrm{ha}^{-1}$ de $\mathrm{N}$ no início do perfilhamento; $\mathrm{N} 3: 80 \mathrm{~kg} \mathrm{ha}^{-1}$ de $\mathrm{N}$ no início do perfilhamento; $\mathrm{N} 4: 40 \mathrm{~kg} \mathrm{ha}^{-1}$ de $\mathrm{N}$ na semeadura; N5: $80 \mathrm{~kg} \mathrm{ha}^{-1}$ de N na semeadura; N6: $40 \mathrm{~kg} \mathrm{ha}^{-1}$ de N na semeadura e $40 \mathrm{~kg} \mathrm{ha}^{-1}$ de N no início do perfilhamento; N7: $20 \mathrm{~kg} \mathrm{ha}^{-1}$ de $\mathrm{N}$ na semeadura e $60 \mathrm{~kg} \mathrm{ha}^{-1}$ de $\mathrm{N}$ no início do perfilhamento. Averages followed by the same letter in the column do not differ by the $F$ test and Tukey's test $(P<0.05)$ for vigor and nitrogen, respectively. $\mathrm{Nl}$ - without $\mathrm{N} ; \mathrm{N2}-40 \mathrm{~kg} \mathrm{ha}^{-1} \mathrm{~N}$ tillering; $\mathrm{N3-80} \mathrm{kg} \mathrm{ha}^{-1} \mathrm{~N}$ tillering; $\mathrm{N4-40} \mathrm{kg} \mathrm{ha}^{-1}$ at

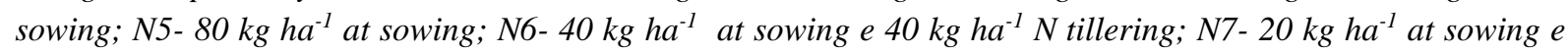
$60 \mathrm{~kg} \mathrm{ha}^{-1} 1 \mathrm{~N}$ tillering.

Fonte: Autoria própria. Own authorship.

Os maiores valores de massa seca de plântulas foram obtidos pelo tratamento N7, que apresentou maiores incrementos, independentemente do nível de vigor das sementes (Tabela 3). Constatou-se diferença entre os tratamentos de alto e baixo vigor quando foram utilizados apenas $40 \mathrm{~kg} \mathrm{ha}^{-1}$ de $\mathrm{N}$ no perfilhamento, sendo favorecidas as sementes de alto vigor, corroborando com os resultados de germinação e comprimento de plântulas para este tratamento. Os menores valores de massa seca para sementes de alto vigor foram observados nos tratamentos $\mathrm{N} 1$ e $\mathrm{N} 3$, ambos com $0 \mathrm{~kg} \mathrm{ha}^{-1}$ de $\mathrm{N}$ na semeadura. Verifica-se que a aplicação de $80 \mathrm{~kg} \mathrm{ha}^{-1}$ de $\mathrm{N}$ no perfilhamento (N3) não foi suficiente para suprir a ausência deste nutriente na semeadura.

Com relação à produtividade, era esperado que plantas oriundas de sementes de alto vigor e altas doses de $\mathrm{N}$ apresentassem maior produtividade em relação aos demais tratamentos, assim como maior massa de mil sementes, mas isto não se confirmou para ambas as variáveis avaliadas. Esse resultado pode estar relacionado à expressão da capacidade de compensação do cultivar por meio da emissão de maior número de afilhos, de maior número de sementes por área ou do aumento na massa de sementes (VALÉRIO et al., 2008), principalmente sob condições favoráveis de ambiente no decorrer do ciclo da cultura.

Para a primeira contagem da germinação (Tabela 4), constatou-se que as sementes produzidas por plantas oriundas de sementes de alto vigor apresentaram maior porcentagem de plântulas normais em relação às sementes provenientes de plantas obtidas a partir de 
sementes de baixo vigor. Para adubação nitrogenada, observou-se que N2, N1 e N7, foram os tratamentos que apresentaram os menores valores para a primeira contagem da germinação.

Tabela 4. Primeira contagem da germinação de sementes de trigo da cultivar BRS GralhaAzul, em função do vigor de sementes e da adubação nitrogenada. First count of wheat seed germination of cultivar BRS Gralha-Azul, depending on seed vigor and nitrogen fertilization.

\begin{tabular}{cccccccc}
\hline \multicolumn{3}{c}{ Alto vigor } & \multicolumn{4}{c}{ Baixo vigor } & \multicolumn{3}{c}{ CV (\%) } \\
\hline \multicolumn{4}{c}{$89 \mathrm{a}$} & \multicolumn{4}{c}{$86 \mathrm{~b}$} \\
\hline \multicolumn{4}{c}{ Nitrogênio } \\
\hline $\mathrm{N} 1$ & $\mathrm{~N} 2$ & $\mathrm{~N} 3$ & $\mathrm{~N} 4$ & $\mathrm{~N} 5$ & $\mathrm{~N} 6$ & $\mathrm{~N} 7$ & $\mathrm{CV}(\%)$ \\
\hline $87 \mathrm{ab}$ & $82 \mathrm{~b}$ & $90 \mathrm{a}$ & $89 \mathrm{a}$ & $91 \mathrm{a}$ & $88 \mathrm{a}$ & $87 \mathrm{ab}$ & 4,18 \\
\hline
\end{tabular}

Nota: Médias seguidas de mesma letra na coluna não diferem entre si pelo teste $\mathrm{F}$ e pelo teste de Tukey $(\mathrm{P}<0,05)$ para vigor e nitrogênio, respectivamente. $\mathrm{N} 1: \mathrm{sem} \mathrm{N} ; \mathrm{N} 2: 40 \mathrm{~kg} \mathrm{ha}^{-1}$ de $\mathrm{N}$ no início do perfilhamento; $\mathrm{N} 3: 80 \mathrm{~kg}$ $\mathrm{ha}^{-1}$ de $\mathrm{N}$ no início do perfilhamento; $\mathrm{N} 4: 40 \mathrm{~kg} \mathrm{ha}^{-1}$ de N na semeadura; N5: $80 \mathrm{~kg} \mathrm{ha}^{-1}$ de $\mathrm{N}$ na semeadura; N6: $40 \mathrm{~kg} \mathrm{ha}^{-1}$ de $\mathrm{N}$ na semeadura e $40 \mathrm{~kg} \mathrm{ha}^{-1}$ de $\mathrm{N}$ no início do perfilhamento; $\mathrm{N} 7: 20 \mathrm{~kg} \mathrm{ha}^{-1}$ de $\mathrm{N}$ na semeadura e $60 \mathrm{~kg} \mathrm{ha}^{-1} \mathrm{de} \mathrm{N}$ no início do perfilhamento. Averages followed by the same letter in the column do not differ by the F test and Tukey's test $(P<0.05)$ for vigor and nitrogen, respectively. $\mathrm{Nl}$ - without $\mathrm{N} ; \mathrm{N2}-40 \mathrm{~kg} \mathrm{ha-} \mathrm{N}$ tillering; N3- $80 \mathrm{~kg} \mathrm{ha^{-1 }} \mathrm{N}$ tillering; $\mathrm{N4-} 40 \mathrm{~kg} \mathrm{ha}^{-1}$ at sowing; $\mathrm{N5}-80 \mathrm{~kg} \mathrm{ha}^{-1}$ at sowing; $\mathrm{N6-} 40 \mathrm{~kg} \mathrm{ha}^{-1}$ at sowing e $40 \mathrm{~kg} \mathrm{ha}^{-1} \mathrm{~N}$ tillering; $\mathrm{N7}-20 \mathrm{~kg} \mathrm{ha}^{-1}$ at sowing e $60 \mathrm{~kg} \mathrm{ha}^{-1} 1 \mathrm{~N}$ tillering.

Fonte: Autoria própria. Own authorship.

O maior vigor das sementes oriundas de plantas estabelecidas com sementes de alto vigor, é explicado em parte, pelo rápido desenvolvimento inicial das plântulas no campo, além de maiores níveis de massa seca da parte aérea, número de folhas, estatura, bem como taxa de crescimento da cultura, o que acarreta elevada produção de fotoassimilados, culminando em maior nutrição do embrião e deposição de reservas nas sementes (LUDWIG et al., 2009). A redução aleatória do estande inicial de plantas, devido ao uso de sementes de baixo vigor, também pode ter influência negativa sobre a qualidade fisiológica das sementes produzidas (BARBIERI et al., 2013).

De maneira geral, o tratamento N7 com aplicação de $80 \mathrm{~kg} \mathrm{ha}^{-1}$ parcelados em 20 e 60 $\mathrm{kg} \mathrm{ha}^{-1}$, na semeadura e no perfilhamento, respectivamente, é considerado controle por ser geralmente recomendado e utilizado na produção de trigo. Este tratamento proporcionou a produção de sementes com maiores níveis de vigor, tanto na utilização de sementes de baixo como de alto vigor, indicando a maior eficiência do parcelamento da adubação nitrogenada.

Porém, com base nos dados obtidos no presente estudo, se o produtor possuir informação sobre o vigor das sementes antes da semeadura e estas possuírem alto vigor, a adubação nitrogenada poderia ser feita em uma única aplicação de $80 \mathrm{~kg} \mathrm{ha}^{-1}$ na semeadura (N5), reduzindo os custos e mantendo a qualidade das sementes produzidas. Uma vez que o tratamento proporcionou elevada germinação e vigor, e não diferiu estaticamente de N7 para os testes realizados quando utilizadas sementes de alto vigor.

\section{CONCLUSÃO}

A adubação com $20 \mathrm{~kg} \mathrm{ha}^{-1}$ de $\mathrm{N}$ na semeadura e $60 \mathrm{~kg} \mathrm{ha}^{-1}$ de $\mathrm{N}$ no início do perfilhamento foi o mais eficiente para a produção de sementes vigorosas da cultivar BRS Gralha-Azul. 
Sementes de alto vigor juntamente com adubação de $80 \mathrm{~kg} \mathrm{ha}^{-1}$ de $\mathrm{N}$ no início do perfilhamento é eficiente para a produção de sementes da cultivar BRS Gralha-Azul com elevada qualidade fisiológica.

Sementes com alto vigor apresentam melhor potencial fisiológico. Os níveis de vigor de sementes e as combinações de épocas de aplicação e doses de nitrogênio não alteram a produtividade e a massa das sementes produzidas.

\section{AGRADECIMENTOS}

O presente trabalho foi realizado com apoio da Coordenação de Aperfeiçoamento de Pessoal de Nível Superior - Brasil (CAPES) - Código de financiamento 001.

\section{REFERÊNCIAS BIBLIOGRÁFICAS}

BARBIERI, A. P. P.; MARTIN, T. N.; MERTZ, L. M.; NUNES, U. R.; CONCEIÇÃO, G. M. Redução populacional de trigo no rendimento e na qualidade fisiológica das sementes. Revista Ciência Agronômica, Fortaleza, v. 44, n. 4, p.724-731, 2013. Disponível em: http://www.scielo.br/pdf/rca/v44n4/08.pdf. Acesso em: 16 jul. 2019.

BASSOI, M. C.; RIEDE, C. R.; CAMPOS, L. A. C.; FOLONI, J. S. S.; NASCIMENTO JÚNIOR, A.; GARBUGLIO, D. D.; ARRUDA, K. M. A. Cultivares de trigo e triticale: Embrapa e IAPAR. Londrina: Embrapa Soja, 2015. 64 p.

BONO, J. A. M.; RODRIGUES, A. P. D. C.; MAUAD, M.; AlbUQUERQUE, J. C.; YAMAMOTO C. R.; CHERMOUTH, K. S.; FREITA, M. E. Modo de aplicação de fertilizantes nitrogenados na qualidade fisiológica de sementes de milho. Agrarian,

Dourados, v. $1, \quad$ n. 2, p.91-102, 2008. Disponível em: http://ojs.ufgd.edu.br/index.php/agrarian/article/view/258/210. Acesso em: 20 jul. 2019.

BRASIL. Ministério da Agricultura e Reforma Agrária. Secretaria Nacional de Defesa Agropecuária. Departamento Nacional de Defesa Vegetal. Regras para análise de sementes. Brasília, 2009. 395 p.

CARVAlHO, N. M.; NAKAGAWA, J. Sementes: ciência, tecnologia e produção. 5. ed. Jaboticabal: FUNEP, 2012. 590 p.

DELOUCHE, J. C.; MATTHES, R. K.; DOUGHERTY, G. M. Storage of seed in sub-tropical and tropical regions. Seed Science and Technology, Zurich, v. 1, n. 3, p.671-700, 1973. Disponível em: https://ir.library.msstate.edu/bitstream/handle/11668/13304/D7.pdf? sequence=1. Acesso em: 14 jul. 2019.

HENNING, F. A.; MERTZ, L. M.; JACOB JUNIOR, E. A.; DORNELES, R. M.; FISS, G.; DEJALMA, P. Z. Composição química e mobilização de reservas em sementes de soja de alto e baixo vigor. Bragantia, Campinas, v. 69, n. 3, p.727-733, 2010. Disponível em: http://www.scielo.br/pdf/brag/v69n3/26.pdf. Acesso em: 16 jul. 2019.

LUDWIG, M. P.; SCHUCH, L. O. B.; LUCCA FILHO, O. A.; AVELAR, S. A. G.; MIELEZRSKI, F.; DE OLIVEIRA, S. A. N. D. R. O.; CRIZEL, R. L. Desempenho de 
sementes e plantas de milho híbrido originadas de lotes de sementes com alta e baixa qualidade fisiológica. Revista Brasileira de Milho e Sorgo, Sete Lagoas, v. 8, n. 1, 2009. Disponível em: http://rbms.cnpms.embrapa.br/index.php/ojs/article/view/272/pdf_175. Acesso em: 16 jul. 2019.

MAGUIRE, J. D. Speed of germination - AID in relation evaluation for seedling emergence and vigor. Crop Science, Madison, v. 2, n. 2, p.176-177, 1962.

MARCOS FILHO, J. Fisiologia de sementes de plantas cultivadas. 2. ed. Londrina: ABRATES, 2015. 660 p.

NAKAGAWA, J. Testes de vigor baseados no desempenho das plântulas. In: KRZYZANOWSKI, F. C.; VIEIRA, R. D.; FRANÇA NETO, J. B. (ed.). Vigor de sementes: conceitos e testes. Londrina: ABRATES, 1999. Cap. 2, p. 2-24.

NAKAO, A. H.; COSTA, N. R.; ANDREOTTI, M.; SOUZA, M. F. P.; DICKMANN, L. D.; CENTENO, D. C.; CATALANI, G. C. Características agronômicas e qualidade fisiológica de sementes de soja em função da adubação foliar com boro e zinco. Cultura Agronômica, Ilha Solteira, v. 27, n. 3, p.312-327, 2018. Disponível em: https://ojs.unesp.br/index.php/rculturaagronomica/article/view/2446-8355.2018v27n3p312327/2033. Acesso em: 31 mar. 2021.

PRANDO, A. M.; ZUCARELI, C.; FRONZA, V.; OLIVEIRA, E. A. P.; PANOFF, B. Formas de ureia e doses de nitrogênio em cobertura na qualidade fisiológica de sementes de trigo. Revista Brasileira de Sementes, Brasilia, DF, v. 34, n. 2, p.272-279, 2012. Disponível em: http://www.scielo.br/pdf/rbs/v34n2/12.pdf. Acesso em: 20 jul. 2019.

SÁ, M. E. Importância da adubação nitrogenada na qualidade de sementes. In: SÁ, M. E.; BUZZETTI, S. Importância da adubação na qualidade dos produtos agrícolas. São Paulo: Icone, 1994. Cap. 4, p. 65-98.

SANTORUM, M.; NÓBREGA, L. H. P.; SOUZA, E. G.; SANTOS, D.; BOLLER, W.; MAULI, M. M. Comparison of tests for the analysis of vigor and viability in soybean seeds and their relationship to field emergence. Acta Scientiarum Agronomy, Maringá, v. 35, n. 1, p.83-92, 2013.

Disponível

em: http://www.scielo.br/scielo.php?script=sci_arttext\&pid=S1807-86212013000100010. Acesso em: 19 jul. 2019.

SCHUCH, L. O. B.; KOLCHINSKI, E. M.; CANTARELLI, L. D. Relação entre a qualidade de aveia-preta e a produção de forragem e de sementes. Scientia Agraria, Piracicaba, v. 9, n. 1, p. 1-6. 2008. Disponível em: https://revistas.ufpr.br/agraria/article/view/10125/8168. Acesso em: 16 jul. 2019.

SCHUCH, L. O. B.; NEDEL, J. L.; MAIA, M. D. S.; ASSIS, F. D. Vigor de sementes e adubação nitrogenada em aveia preta (Avena strigosa Schreb.). Revista Brasileira de Sementes, Brasília, DF, v. 21, n. 2, p.127-134, 1999. Disponível em: https://www.agrolink.com.br/downloads/82900.pdf. Acesso em: 20 jul. 2019.

SILVA, S. R.; BASSOI, M. C. FOLONI, J. S. S. Informações técnicas para trigo e triticale. Brasília, DF: Embrapa, 2017. 240 p. 
TODESCHINI, M. H.; MILIOLI, A. S.; TREVIZAN, D. M.; BORNHOFEN, E.; FINATTO, T.; STORCK, L.; BENIN, G. Eficiência de uso do Nitrogênio em cultivares modernas de trigo. Bragantia, Campinas, v. 75, n. 3, p.351-361, 2016. Disponível em: http://www.scielo.br/pdf/brag/2016nahead/pt_0006-8705-brag-1678-4499385.pdf. Acesso em: 16 jul. 2019.

VALÉRIO, I. P.; CARVALHO F. I. F.; OLIVEIRA, A. C.; MACHADO, A. A.; BENIN, G.; SCHEEREN, P. L.; SOUZA, V. Q.; HARTWIG, I. Desenvolvimento de afilhos e componentes do rendimento em genótipos de trigo sob diferentes densidades de semeadura. Pesquisa Agropecuária Brasileira, Brasília, v. 43, n. 3, p.319-326, 2008. Disponível em: http://www.scielo.br/pdf/pab/v43n3/a05v43n3.pdf. Acesso em: 20 jul. 2019.

VIEIRA, R. D.; KRZYZANOWSKI, F. C. Teste de condutividade eletrica. In: KRZYZANOWSKI, F. C.; VIEIRA, R. D.; FRANCA NETO, J. B. (ed.). Vigor de sementes: conceitos e testes. Londrina: ABRATES, 1999. Cap. 4, p.1-26. 